\title{
Interrelationship between adipocytes and fibroblasts during acute damage to the subcutaneous adipose tissue of rats: an ultrastructural study
}

Z.A. Andrade, J. de-Oliveira-Filho and A.L.M. Fernandes
Laboratório de Patologia Experimental, Centro de Pesquisas Gonçalo Moniz, FIOCRUZ, Salvador, BA, Brasil
Correspondence

Z.A. Andrade

Rua Valdemar Falcão, 121

40295-001 Salvador, BA

Brasil

Received July 22, 1997

Accepted February 27, 1998

\section{Abstract}

Ultrastructural phenotypic transitional features were noted between adult adipocytes and fibroblasts in the subcutaneous adipose tissue of the dorsal pad of normal adult Wistar rats of both sexes, weighing 180$260 \mathrm{~g}$, after acute injury either by the implantation of small $(1.8 \times 1 \times$ $0.4 \mathrm{~cm}$ ) perforated plastic boxes or by local heat application. Soon after the inflicted damage, fat-containing cells presented variable shapes. Early after damage, some of these cells were round, adipocytelike, with numerous and large cytoplasmic fat droplets. A few days later, fat-containing cells became elongated, with the fat droplets in their cytoplasm becoming smaller and less numerous. The cells also showed a prominent active rough endoplasmic reticulum and newly formed collagenous matrix accumulated in the interstices. Although current views consider adult adipocytes to be terminal cells, the present findings, in their time sequence, strongly suggest the transformation of adipocytes into fibroblasts after acute injury to adipose tissue.

\section{Introduction}

It has been demonstrated that lipocytes (Ito's cells), perisinusoidal fat-storing cells residing in the liver, can be transformed into myofibroblasts and fibroblasts $(1,2)$. Also, there is general agreement that fibroblasts can be transformed into adipocytes, a situation mimicking embryonic development when precursor fibroblast-like cells give origin to adipose tissues (3-5). However, the adult adipocytes in the fat depots are considered to be terminal cells $(6,7)$. Despite the
Key words

- Adipocytes

- Adipocyte potential

for differentiation

- Adipose tissue damage fact that in vitro findings have revealed omental adipocytes to lose their spherical shape and regain their pre-adipocyte appearance and their capacity to replicate (8), it has been stated that "the adipose cells never revert to simple fusiform cells resembling pre-adipocytes or fibroblasts" (7).

In the present investigation we describe ultrastructural findings obtained for acutely damaged subcutaneous adipose tissue of rats, which revealed phenotypic transitional features between adipocytes and fibroblasts. These findings, when analyzed within a time 
sequence, are strongly suggestive of the differentiation of adult adipocytes into fibroblasts. Although the risk of misinterpretation does exist whenever a series of static features are interpreted from a dynamic viewpoint, this exercise remains a valid one in pathology. However, considering the methodologic limitations, the present interpretation is offered as a working hypothesis to be further explored with the tools of molecular biology.

\section{Material and Methods}

Normal adult Wistar rats of both sexes weighing 180-260 $\mathrm{g}$ and receiving a balanced commercial diet and water ad libitum were used throughout the experiments. Material from the dorsal fatty tissue pad of rats was examined after two sets of experiments.

In the first experiment, a small sterile perforated plastic box, measuring $1.8 \times 1 \mathrm{x}$ $0.4 \mathrm{~cm}$, was implanted into the dorsal area of rats in order to study the connective tissue reaction leading to the formation of an isolating capsule around it. Techniques related to the preparation and implantation of the boxes are detailed elsewhere $(9,10)$. The boxes were removed from 2 animals each week over a period of two months.

In the second experiment, 15 animals were anesthetized with ether and, after a small surgical incision in the shaved dorsal skin under sterile conditions, an incandescent thin wire was instantaneously introduced and removed through the dorsal subcutaneous adipose tissue. The cutaneous incision was then sutured and the animals recovered from anesthesia uneventfully. The lesion area was removed 1, 3, 7, 14 and 21 days later.

Tissues from both experiments were fixed in $10 \%$ phosphate buffered formalin and embedded in paraffin. Histological $5-\mu \mathrm{m}$ sections were stained with hematoxylin and eosin, picro-sirius red for collagen, and orcein for elastic fibers.
For electron microscopy tiny fragments of tissues were immediately placed in $2 \%$ glutaraldehyde in cacodylate buffer, $\mathrm{pH}$ 7.2, for $2 \mathrm{~h}$, washed several times in the buffer and post-fixed in $1 \%$ osmium tetroxide for 1 h. After progressive dehydration in acetone the fragments were embedded in Polybed resin. Semithin sections were examined for the selection of suitable areas for electron microscopy. Selected blocks were cut with a Reichert Trucut ultramicrotome using a diamond knife. Ultrathin sections were contrasted with uranyl acetate and lead citrate and examined with an EM-109 Zeiss electron microscope at $50 \mathrm{mV}$.

\section{Results}

Light microscopy

Tissues from both experiments showed acute and chronic inflammation involving the adipose tissue. Necrosis, hemorrhage and disintegration of fatty tissue were observed after the first days of heat damage, followed by considerable proliferation of fibroblasts and formation of new blood capillaries (granulation tissue) one week after the inflicted damage. The presence of edema and infiltration by polymorphonuclear leukocytes was prominent from the 3rd through the 7th day. Some rounded macrophage-like or fusiform, fibroblast-like cells were then observed, exhibiting cytoplasmic macro- and microvacuolation. After the first week these changes gradually increased and progressed to the formation of large fibrous septa. Early changes in the first experiment were less severe and consisted of the formation of granulation tissue around the plastic box. Later changes led to the formation of a fibrous capsule with abundant and dense collagenous fibers.

\section{Electron microscopy}

Tissue analyzed within the first week 
after adipose tissue damage in both experiments showed isolated cells with large fat droplets comparable to adult adipocytes, side by side with others exhibiting numerous small fat droplets (Figure 1). These fat droplets appeared smaller and more numerous in other cells (Figure 2). At the same time, a conspicuous endoplasmic reticulum, forming cisternae filled with amorphous secretory material, was noted between the fat droplets.

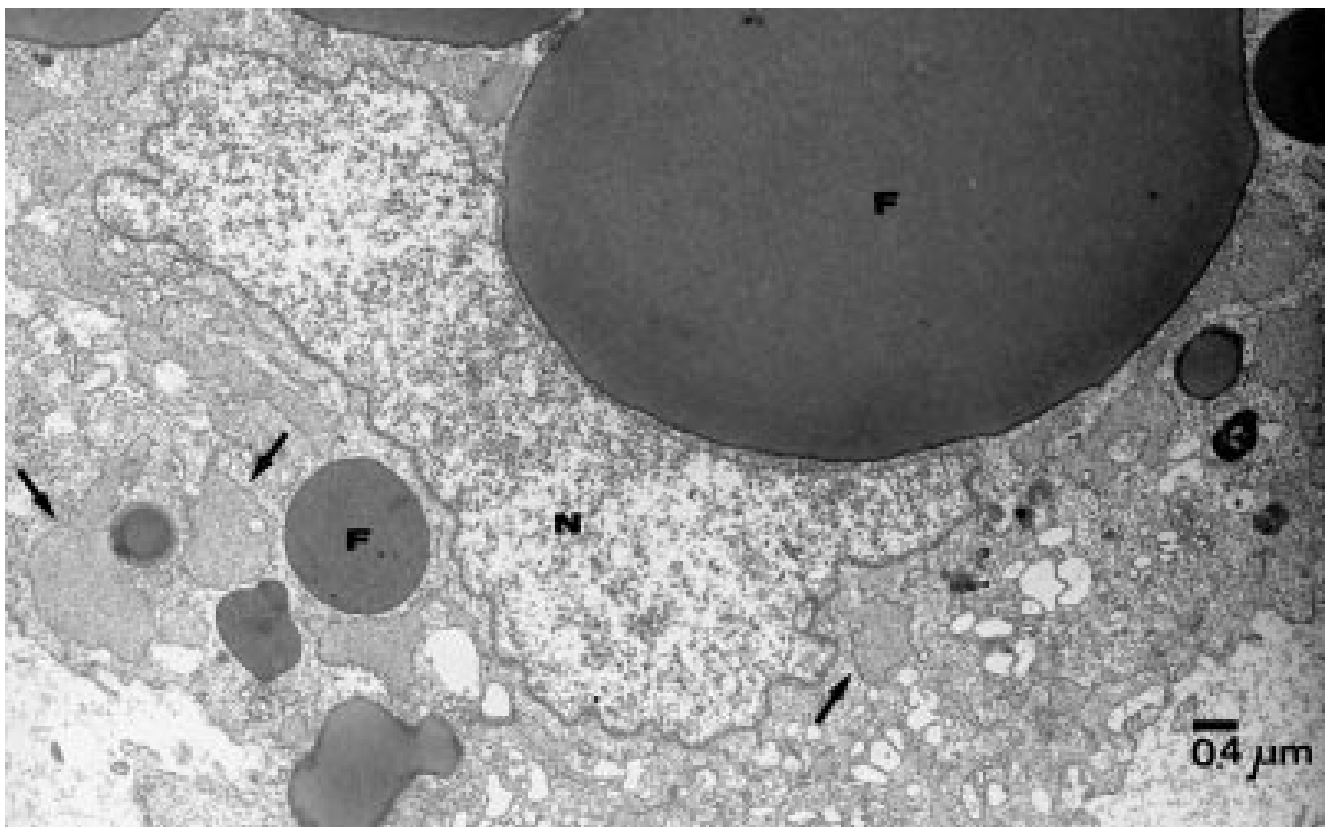

Figure 1 - Electron photomicrograph showing fat-storing cell one week after acute damage of the rat subcutaneous tissue. There are large fat droplets (F) and development of a rough endoplasmic reticulum forming cisternae filled with amorphous secretory material (arrows). $\mathrm{N}=$ Nucleus. 7,000X.

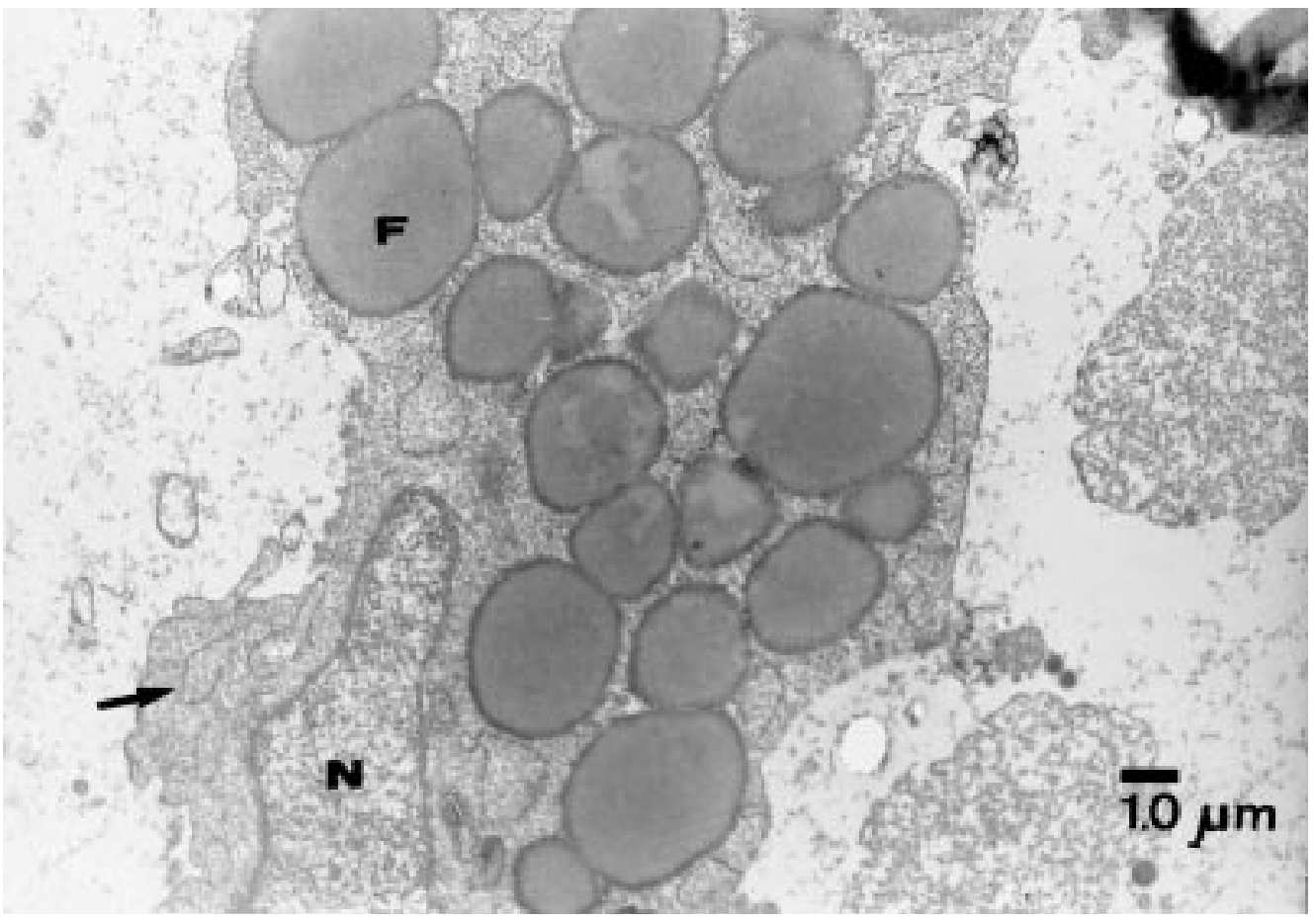

Figure 2 - Electron photomicrograph showing a cell among cellular debris on the 3rd day following heat damage of the rat subcutaneous fat tissue. Numerous round fat droplets $(\mathrm{F})$ appear accumulated in the cytoplasm of an elongated cell with an inconspicuous rough endoplasmic reticulum (arrows). $\mathrm{N}=$ Nucleus. $7,000 X$. 
In the subsequent samples taken after the first week the fat-loaded round cells were apparently replaced by more elongated cells containing smaller and less numerous fat droplets in the cytoplasm (Figure 3). This

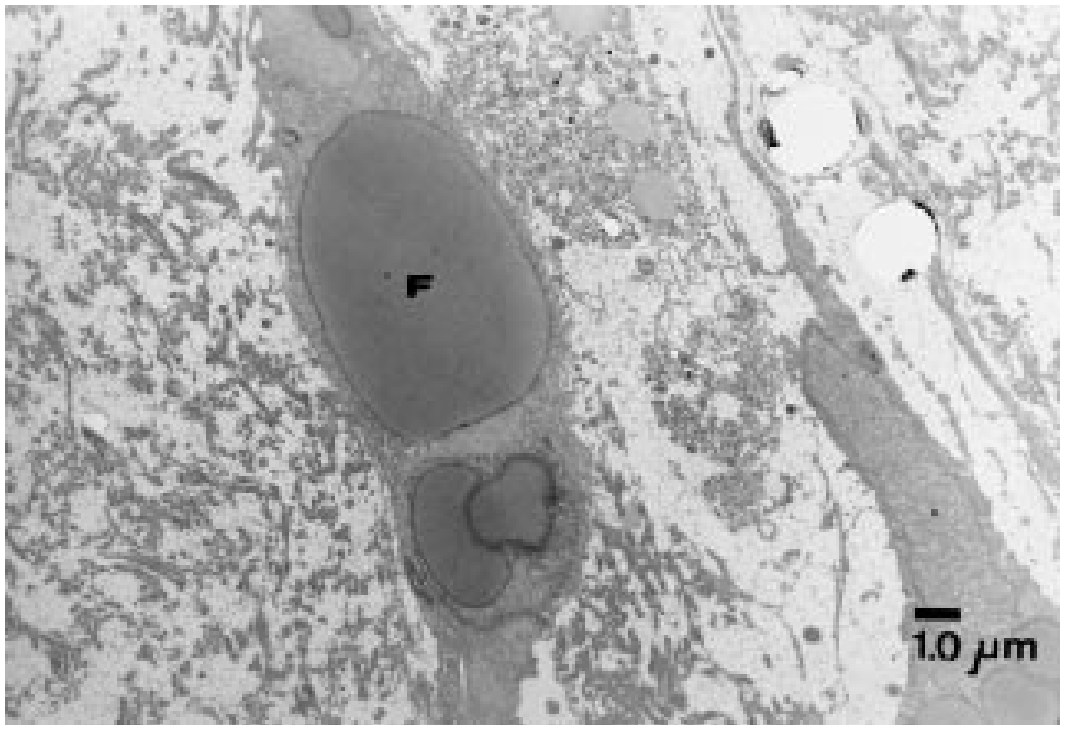

Figure 3 - Electron photomicrograph showing elongated fat-containing cells distributed in parallel within an edematous matrix containing cellular debris and loosely distributed collagen fibrils one week after damage. F = Fat droplet. 7,000X.

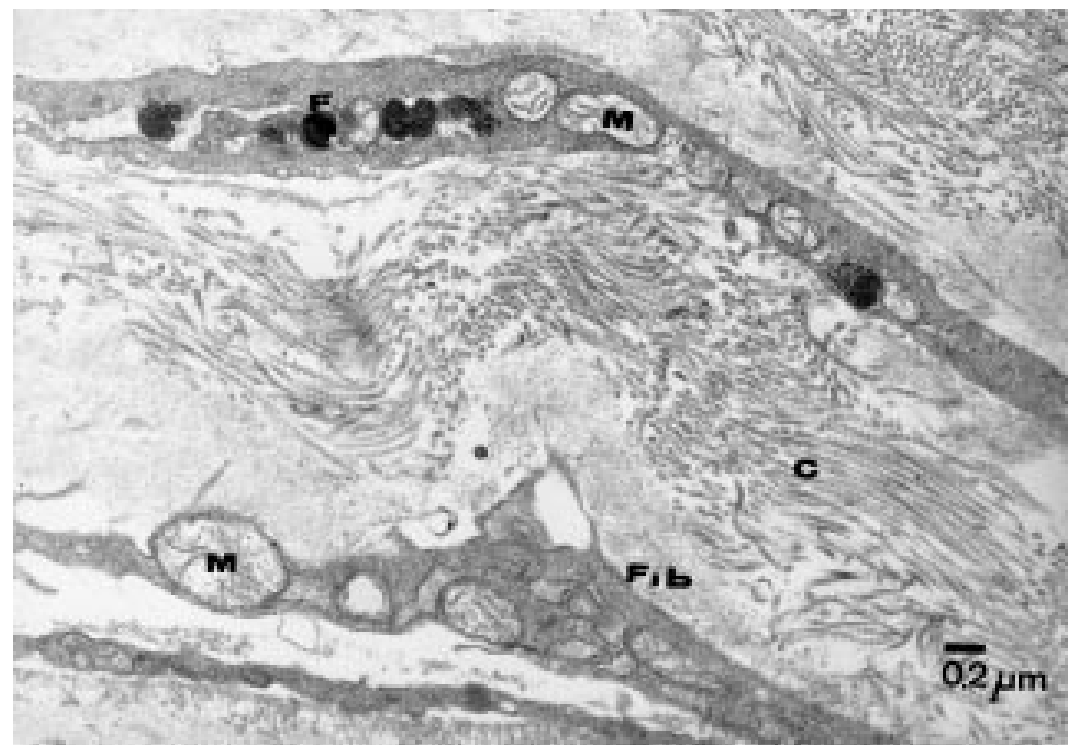

Figure 4 - Electron photomicrograph showing well-formed fibrous tissue with abundant collagenous matrix and two fibroblasts (Fib), one of them containing small fat droplets (F). These features were observed both after heat damage and two weeks after implantation of a plastic box into the dorsal subcutaneous tissue of rats. $\mathrm{M}=$ Mitochondrion, $\mathrm{C}=$ collagen fibrils. 4,400X. transformation also coincided with the appearance of a prominent rough endoplasmic reticulum and an increased number of mitochondria. In the vicinity of these cells there was a progressive deposition of collagen fibrils, irregularly displayed at first and later forming parallel bundles of fibers. In other areas, findings included an increased extracellular matrix, with numerous parallel collagen fibrils and fibers and elongated thin fibroblast-like cells arranged in parallel rows and some of them showing few small fat droplets in the cytoplasm (Figure 4).

\section{Discussion}

The "fibroblast family" concept (11) postulates that a group of cells, such as Ito's cells, myofibroblasts, fibroblasts, osteoblasts, osteocytes, chondrocytes, smooth muscle cells and adipocytes, appear to have a common origin and to share the capacity to differentiate into one another. As a matter of fact, the adaptability of their differentiated character is an important feature of the responses to many types of damage. However, although differentiation of these cell types is often interconvertible, transformation of fibroblasts into adipocytes is considered to be a one-way phenomenon, at least as far as the mature fat cell is concerned $(6,7)$. Ultrastructural evidence of the contrary is now presented.

The present results originated from casual electron microscopy findings during examination of connective tissue grown around perforated plastic boxes. When a perforated plastic box is implanted into the subcutaneous tissue of a rat, granulation tissue grows around it, penetrates through the holes and continues to grow under the inner surface, thus creating a double fibrous capsule that "sequesters" the box $(9,10)$. The interior of the box is then filled with a clear liquid exudate. Transitional features between adipocytes and fibroblasts were first noted when these capsules were examined. These 
features were also present when a second experiment was performed. In this experiment, acute focal damage to the adipose subcutaneous tissue of the rat was inflicted by local heat application. Confirming the first observations, ultrastructural findings showed transitional features between adult adipocytes and fibroblasts. However, it is rather difficult to evaluate in which direction differentiation is taking place by simply analyzing different static morphologic pictures. The present findings were considered to be more consistent with a transformation of adipocytes into fibroblasts rather than vice versa. Basically, the time sequence, initially showing cells with large and multiple fat droplets and, later on, the appearance of progressively elongated cells, where fat globlets tended to decrease in size and number while rough endoplasmic reticulum became more and more prominent, was a decisive factor in that interpretation.

However, other possibilities can be contemplated. One of them is intracellular fat disintegration in adipocytes being followed by rupture and phagocytosis of fat droplets by macrophages and fibroblasts. The phagocytic activity of fibroblasts is well known $(12,13)$. Although vacuolated macrophagelike cells were seen by light microscopy in both experiments, evidence of lipid phagocytosis by macrophages was obtained ultrastructurally only in heat-damaged tissue.
However, if both changes occurred, i.e., disintegration of adipocytes and phagocytosis of fat droplets by fibroblasts, the resulting ultrastructural picture would be closely similar to that now being considered. Another possibility would be that fibroblasts transform into adipocytes. Evidence of "fatty metaplasia" or "fatty infiltration" in connective tissues is abundant in the literature. Fatty tissue can be seen "infiltrating" the right ventricular myocardium in obese persons (14), can replace a large part of the pancreatic interstitial tissue (lypomatosis) (15), can fill the lumen of the fibrosed appendix or replace parts of the conducting tissue of the heart in Chagas' disease (16). Infiltrative growth is a prerogative of transformed (neoplastic) cells. It is more likely that fat accumulates in pre-existing connective tissue cells rather than resulting from migration or replication of differentiated adipocytes. The adipocyte itself seems to be a more differentiated (almost resting) connective tissue cell, specialized in storing relatively large amounts of neutral fat. However, it seems that during acute damage some unexpected changes can occur in these cells. This has been little explored in the past. Further studies on the pathology of acute adipose tissue damage will probably reveal that the adipocyte has the same plasticity as the other members of the "fibroblast family".

\section{References}

1. Mak KM, Leo MA \& Lieber CS (1984). Alcoholic liver injury in baboons: transformation of lipocytes to transitional cells. Gastroenterology, 87: 188-200.

2. Gressner AM \& Bachem MG (1990). Cellular sources of non-collagenous matrix proteins: role of fat-storing cells in fibrogenesis. Seminars in Liver Diseases, 10: 30-46.

3. Su HL, Malbon CC \& Wang HY (1993). Increased expression of $\mathrm{Gi}$ alpha 2 in mouse embryo stem cells promotes terminal differentiation to adipocytes. American Journal of Physiology, 265: 729-735.
4. Vassaux G, Négrel R, Ailhaud G \& Gaillard $D$ (1994). Proliferation and differentiation of rat adipose precursor cells in chemically defined medium: differential action of anti-adipogenic agents. Journal of Cellular Physiology, 161: 249-256.

5. Yamashita II, Ohishi S, Kizaki T, Nagasawa J, Saitoh D, Ohira Y \& Ohno II (1995). Insulin stimulates the expression of basic fibroblast growth factor in rat brown adipocyte primary culture. European Journal of Cell Biology, 68: 8-13.

6. Brownell HL, Narsimhan RP, Corbley MJ, Mann VM, Whitfield JF \& Raptis L (1996).
Ras is involved in gap junction closure in proliferating fibroblasts or preadipocytes but not in differentiated adipocytes. DNA and Cell Biology, 15: 443-451.

7. Fawcett DW \& Bloom W (1986). A Textbook of Histology. 12th edn. Chapman \& Hall, New York.

8. Roncari DA, Kindler $\mathrm{S} \&$ Hollenberg $\mathrm{CH}$ (1986). Excessive proliferation in culture of reverted adipocytes from massively obese persons. Metabolism, 35: 1-4.

9. Garra A \& Baygorria GC (1959). Produccion local de anticuerpos. Anales de la Facultad de Medicina, Universidad de la 
Republica, Montevideo, 44: 544-547.

10. Ueda AK (1976). Técnica do "granuloma imunitário". Aspectos morfológicos e imunológicos. Aplicação ao estudo experimental da infecção pelo Trypanosoma cruzi. Master's thesis, Faculdade de Medicina, Universidade Federal da Bahia, BA, Brasil.

11. Alberts B, Bray D, Lewis J, Raff M, Roberts K \& Watson JD (1994). Molecular Biology of the Cell. 3rd edn. Garland Publishers, Inc., New York, 1179-1181.

12. Hail SE, Savill JS, Henson PM \& Haslett C (1994). Apoptotic neutrophils are phago- cytosed by fibroblasts with participation of the fibroblast vitronectin receptor and involvement of a mannose/fucose-specific lectin. Journal of Immunology, 153: 3218-3227.

13. Kirshenbaum AS, Golf JP, Albert JP, Kessler SW \& Metcalfe AA (1994). Fibroblasts determine the fate of $F_{C}$ epsilon $\mathrm{RI}+$ cell populations in vitro by selectively supporting the viability of mast cells while internalizing and degrading basophils. International Archives of Allergy and Immunology, 105: 374-380.

14. Silvestri F \& Bussani R (1990). Hypoxic right ventricular cardiomyopathy. Morphological and pathogenetic study on the myocardial atrophy and fatty infiltration. Pathologica, 82: 593-616.

15. Karademir M, Kocak M, Usal A, Kocak R, Tunali N \& Kaya M (1990). A case of infiltrating lipomatosis with diffuse, symmetrical distribution. British Journal of Clinical Practice, 44: 728-730.

16. Andrade ZA, Andrade SG, Sadigursky M \& Câmara E (1988). Pathology of complete atrioventricular block in chronic chagasic myocarditis. Revista da Sociedade Brasileira de Medicina Tropical, 21: 7-13. 